\title{
frontiers
}

FOR YOUNG MINDS

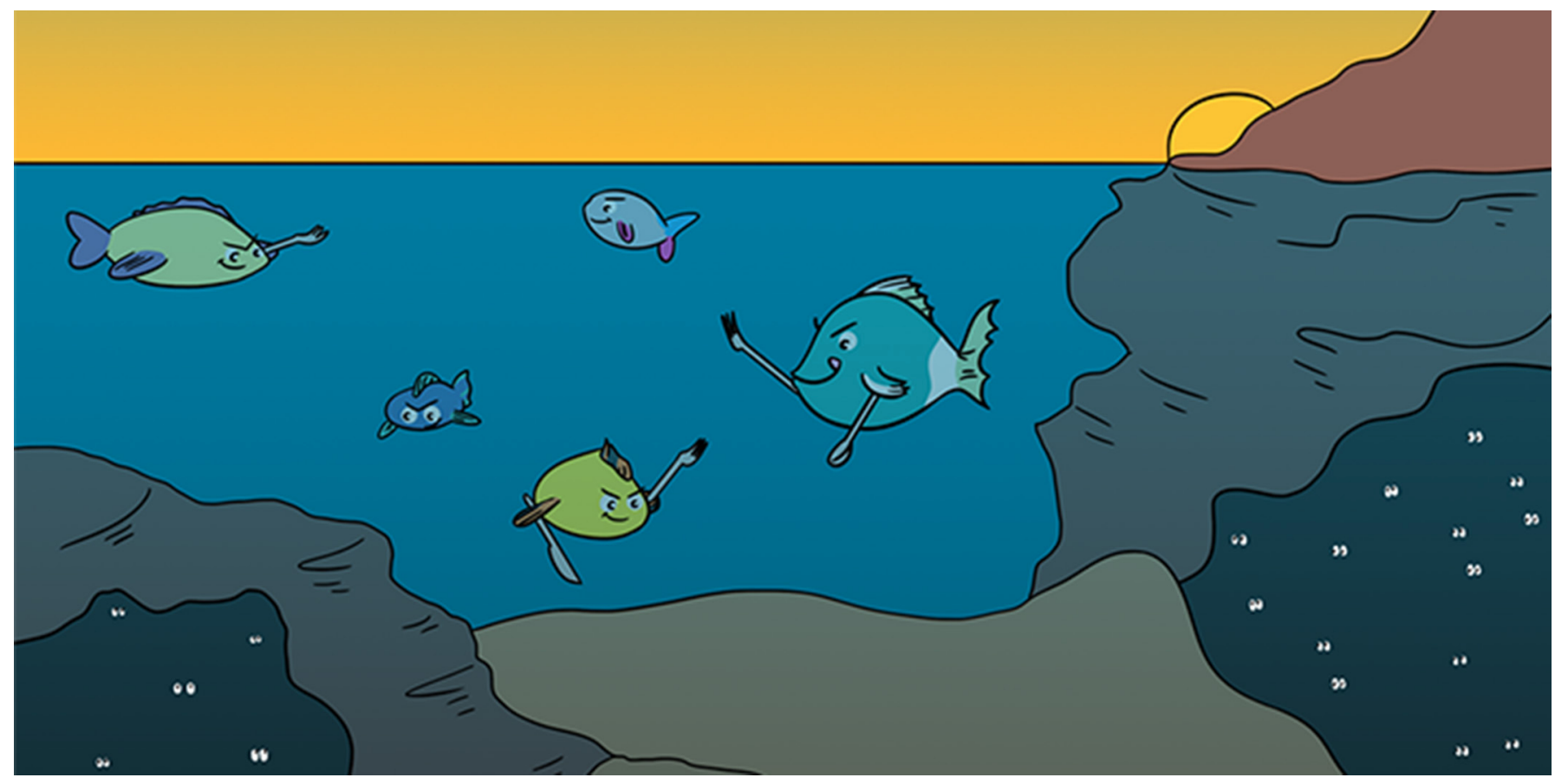

\section{DVM: THE WORLD'S BIGGEST GAME OF HIDE-AND-SEEK}

\section{Jennifer J. Freer ${ }^{1 *}$ and Laura Hobbs ${ }^{2,3}$}

${ }^{1}$ British Antarctic Survey, Cambridge, United Kingdom

${ }^{2}$ Scottish Association for Marine Science, Oban, United Kingdom

${ }^{3}$ Department of Mathematics and Statistics, University of Strathclyde, Glasgow, United Kingdom

YOUNG REVIEWER:

GEMMA

AGE: 16
Diel vertical migration (DVM) refers to the daily, synchronized movement of marine animals between the surface and deep layers of the open ocean. This behavior is the largest animal migration on the planet and is undertaken every single day by trillions of animals in every ocean. Like a big game of hide-and-seek, animals that perform DVM spend the day hiding from predators in the deep ocean, and then migrate to the surface to feed under the cover of darkness. In this article we will explore this incredible strategy for survival. We will introduce the animals involved, describe how the environment of the open ocean drives DVM, and reveal the questions still to be answered as the ocean environment continues to change.

\section{WHAT IS DIEL VERTICAL MIGRATION?}

Flocks of birds flying south for the winter and giant herds of wildebeest searching for green pasture in the Serengeti are some familiar 
DIEL VERTICAL

MIGRATION (DVM)

The daily, synchronized movement of marine animals between the surface and deep layers of the ocean.

\section{EPIPELAGIC}

The surface layer of the open ocean between 0 and $200 \mathrm{~m}$ deep. In this layer there is enough light for phytoplankton to grow.

\section{MESOPELAGIC}

The middle layer of the open ocean between 200 and $1,000 \mathrm{~m}$ deep. Light rapidly declines in this layer and is often called the

"twilight zone."

1 www.mbari.org/canonspring-2019/ (accessed June 26, 2019).

\section{ZOOPLANKTON}

A diverse group of marine animals that are mostly microscopic in size, but can include jellyfish and the eggs of larger animals.

Zooplankton can swim or propel themselves to find food and mates locally, but can only travel large distances across the sea by drifting with the currents.

\section{PREDATOR}

An animal that obtains food by hunting and consuming other animals.

\section{PHYTOPLANKTON}

Microscopic marine plants that are the base of the food chain in the sea. Just like plants on land, phytoplankton require sunlight in order to live and grow. examples of animal migrations. Diel vertical migration (DVM) is less well-known but we think you will find it equally fascinating. DVM describes the synchronized movement of marine animals between the surface and deep layers of the open ocean. This behavior takes place every day, in every ocean, and by biomass it is the largest migration on the planet!

To better understand this behavior, let us separate DVM into its separate words. Diel means that it occurs on a daily, 24-h cycle. Vertical refers to the direction of the movement up and down in the water column, generally between the surface layer (called the epipelagic layer) and the deeper, middle layer (called the mesopelagic layer). That covers a distance of up to $1,000 \mathrm{~m}$ and for the small, oceanic animals called zooplankton that perform DVM, this is an impressive journey;

"It is an enormous movement on their scale. If you scaled it to a human, that would be like running a $10 \mathrm{~K}$ to get your dinner and then a $10 \mathrm{~K}$ before you went to bed, and doing it at twice the speed of an Olympic marathon runner," said Senior Scientist Kelly Benoit-Bird from MBARI ${ }^{1}$.

Finally, migration tells us that this is a mass movement of animals. In fact, by biomass (the total mass of animals in a given area) it is considered to be the largest migration of animals on the planet. For example, just the small migrating fishes have an estimated global weight of more than 1,000 million tons [1]! The word migration also gives us a clue that DVM is not random or done for fun, but that it serves an important purpose-to help the animals survive.

\section{WHY DO ANIMALS DO THIS?}

So, how does a daily marathon of such distance help these animals to stay alive?

Let us set the scene. In the ocean, light changes through the water column, creating sunlit surface water and dark deep water. This light also changes throughout the day. These light conditions, changing in both depth and time, are important for driving DVM behavior.

Zooplankton are bite-sized, energy-rich snacks for many predators, such as fish, whales, and seabirds. These predators are fast and use their eyes to detect their food, which means that they are most effective at hunting during the day and in the sunlit surface water. However, the zooplankton's food source, tiny plants known as phytoplankton, are also only found in the surface water.

So, the zooplankton face a dilemma: if they stay in the surface waters to feed, they risk being eaten. If they hide in the deep, they will be 
Figure 1

Light, food, and predation risk drive diel vertical migration (DVM) of zooplankton and fishes. When it is dark, zooplankton and small fishes rise to feed in the epipelagic waters under the cover of darkness. When it is light, they migrate back to the safety of the darker mesopelagic depths. Animals and phytoplankton are not drawn to scale.

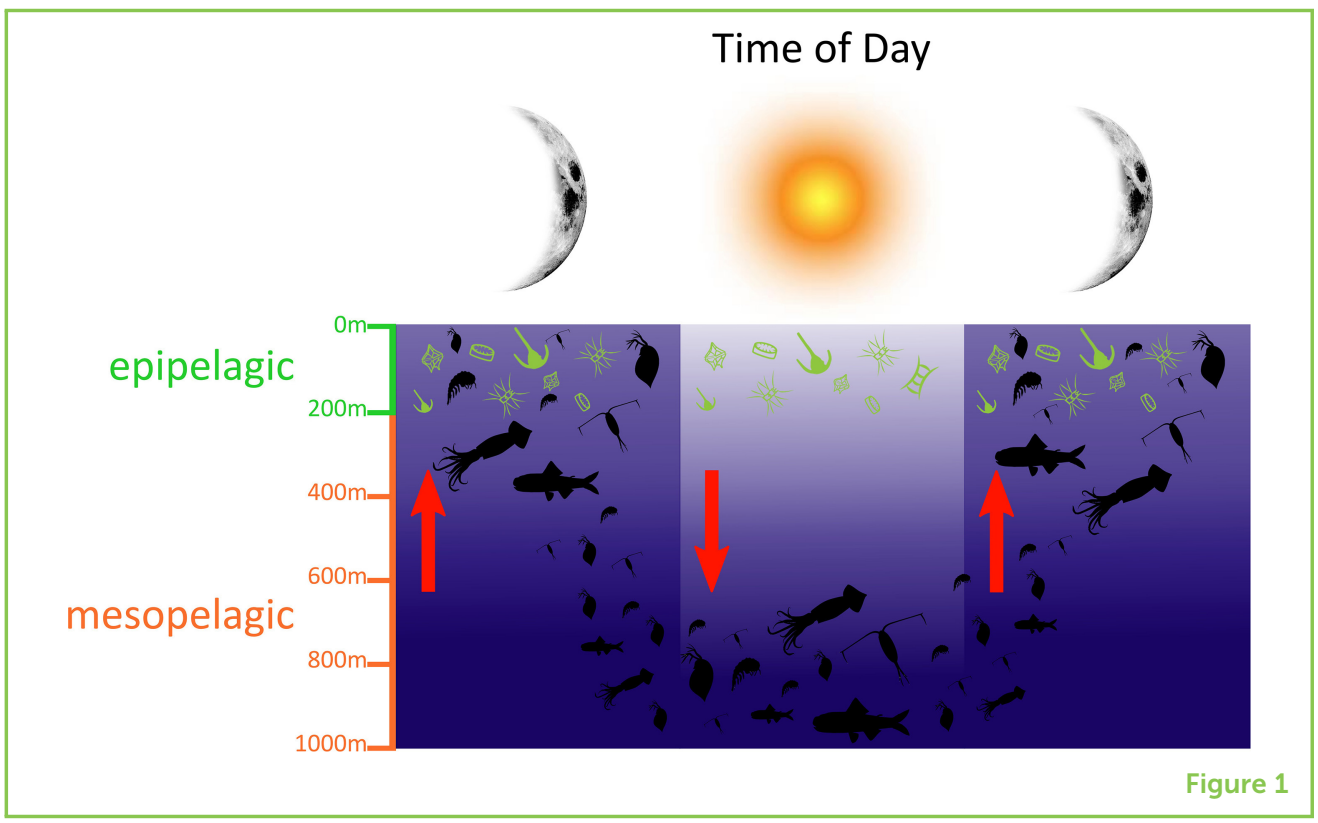

safer, but soon starve. This is what we call a tradeoff: each option (to feed or to hide) brings with it a gain, but also a cost. DVM is the zooplankton's clever solution to balance this tradeoff and have the best of both [2].

Much like a game of hide-and-seek, the zooplankton remain in the deep, dark waters during daylight hours, out of sight of their predators. Under the cover of nightfall, they migrate upwards from the mesopelagic layer to the epipelagic layer, where they can graze in the relative safety of darkness at night (Figure 1).

\section{WHEN DO OCEAN ANIMALS MIGRATE THIS WAY?}

Zooplankton want to feed for the longest time possible, but they also want to avoid the surface during daylight. As a result, they have finely tuned their migrations to the timing of sunrise and sunset-migrating up when the sun sets and migrating down when the sun rises (Figure 1).

Because of the seasons, the time of up- and down-migrations changes through the year. In spring and autumn, day and night last about $12 \mathrm{~h}$ each across most of the planet. But in winter, the days are very short and the nights very long, meaning that sunrise is much later, and sunset is much earlier, with the opposite occurring in summer. We see these changes reflected in the timing of zooplankton migrations.

An exception to this rule is at high latitudes-the Arctic and the Antarctic. Here, the seasons are so pronounced, and the days become so short in the winter, that daylight fails to exist for months at a time. During this period, called the polar night, it is dark $24 \mathrm{~h}$ a day. So, 
Figure 2

\section{Examples of}

zooplankton and fish groups that live in the mesopelagic zone and may perform DVM: (A) sea butterfly (credit: R. Hopcroft, NOAA); (B) copepod (credit: U. Kils); (C) siphonophore (credit: K. Raskoff, NOAA); (D) amphipod (credit: E. A.

Lazo-Wasem); (E)

Hatchetfish feeding on a crustacean (credit: F. Costa); (F) glass squid (credit: E. Widder, NOAA); (G) comb jelly (credit: A. Semenov);

(H) decapod (credit: S. Fielding); and (I) dragonfish (credit: E. Widder/HBOI, NOAA).

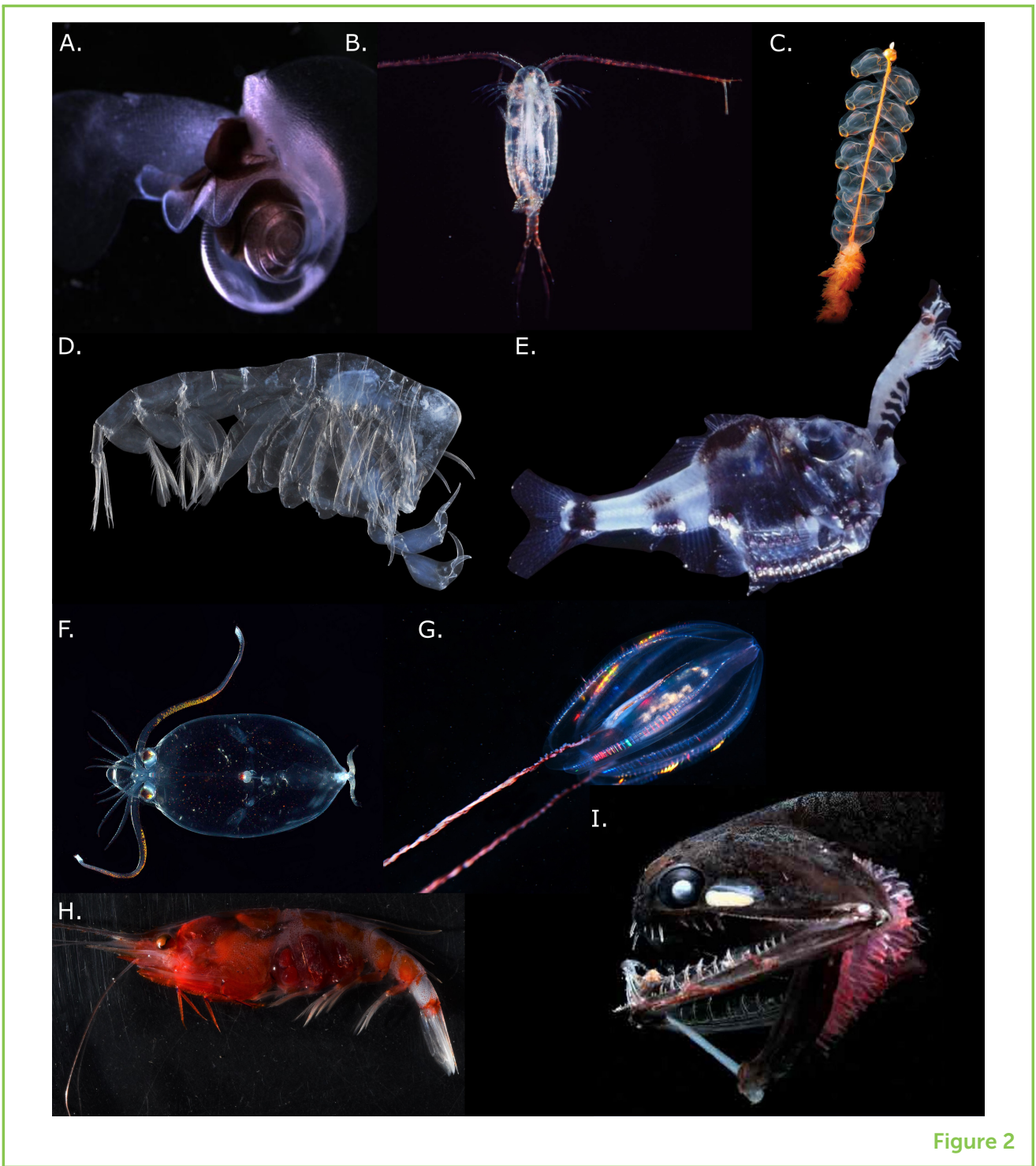

what do the zooplankton do? We used to think that they went into hibernation at this time. But recent research has shown us that some stay awake right through the winter [3]. Instead of migrating in time with the sun, they start to migrate in response to moonlight [4].

\section{WHICH OCEAN ANIMALS PERFORM DVM?}

When we use the word zooplankton, we are really referring to a hugely diverse group of animals. They can vary in size from less than a millimeter long to much larger examples, such as jellyfish. Zooplankton can look very different from each other, but they are united by the definition that, although they are able to weakly swim or propel themselves in the water column, they can only travel large distances across the sea by drifting with the currents. Some examples of zooplankton can be seen in Figure 2 . 
Zooplankton are really important for our ecosystems. Many zooplankton eat phytoplankton and turn this into an energy source. When the phytoplankton-eating zooplankton are eaten themselves, the energy from the phytoplankton becomes available to bigger zooplankton, fish, and even whales. So, DVM affects animals far higher up the food chain than just the zooplankton themselves. It is not just zooplankton that perform DVM. DVM has been seen in fish, and even some sharks perform a version of DVM. So, this is not one simple game of hide-and-seek. It is zooplankton hiding from their predators (such as small fish), who are also doing DVM to hide from their predators (big fish). And this massive game is happening every night, right beneath the waves.

\section{WHERE DOES DVM OCCUR?}

If you look in any sea, ocean, or lake across the planet at any time, you will find animals doing DVM. At sunset every night, they swim to the surface and, at sunrise, they sink to depth. DVM happens everywhere! The exact timings change. Away from the equator, the days are longer in summer and shorter in winter, and the timings of the migrations reflect this. At the equinoxes, on 21st of September and 21st of March, day length is consistent right across the planet. In theory, all the migrators should be swimming to the surface at about 6 o'clock in the evening. As the earth rotates and the sun sets, the migrators start swimming. Imagine it like a huge stadium wave across the world's water bodies.

\section{WHAT IS NEXT?}

Scientists are continually generating new ideas about what controls the timing, depths, and duration of DVM. Evidence now suggests that DVM may not be as simple as a direct response to light. In fact, the temperature and oxygen levels of the water, and even the genetic make-up of individual animals, are other factors that determine where animals are positioned in the water column over the daily cycle [2].

As the oceans continue to warm with climate change, scientists also want to understand how changing environments will affect DVM. For example, fish and zooplankton are moving north to stay within their optimal temperature ranges. This may bring them in to new light conditions, exposing them to longer days in summer and shorter days in winter [5]. How might this new light environment affect their migrations? Will they adapt their finely tuned strategy, or will populations experience lower rates of survival?

Scientists are interested in these questions because zooplankton and their DVM are of huge importance. This is because, after feeding 
all night at the surface, the zooplankton migrate to depths, taking their carbon-filled poo with them. These poo pellets act as speedy vehicles for carbon, which can be locked up for thousands of years when it reaches the bottom of the sea [6]. As the levels of carbon in our atmosphere are contributing to global heating, any changes to zooplankton populations could have big consequences for the efficiency of this carbon removal and for the ocean's ability to help regulate global climate.

Overall, the phrase "better to be hungry than dead" [7] neatly summarizes the reason why so many animals undergo the gargantuan game of hide-and-seek known as DVM. By feeding at night and hiding during the day, DVM allows them to balance their need to eat with avoiding to be eaten! DVM is essential for understanding these mighty migrators and their many roles in the open ocean. You might say it is game-changing.

\section{ACKNOWLEDGMENTS}

We would like to thank the reviewers, science mentor, Anna Belcher, and Gareth Flint for greatly improving the text of the manuscript.

\section{REFERENCES}

1. Irigoien, X., Klevjer, T. A., Rostad, A., Martinez, U., Boyra, G., Acuna, J. L., et al. 2014. Large mesopelagic fishes biomass and trophic efficiency in the open ocean. Nat. Commun. 5:3271. doi: 10.1038/ncomms4271

2. Brierley, A. S. 2014. Diel vertical migration. Curr. Biol. 24:R1074-6. doi: 10.10 16/j.cub.2014.08.054

3. Berge, J., Cottier, F., Last, K. S., Varpe, O., Leu, E., Soreide, J., et al. 2009. Diel vertical migration of Arctic zooplankton during the polar night. Biol. Lett. 5:69-72. doi: 10.1098/rsbl.2008.0484

4. Last, K. S., Hobbs, L., Berge, J., Brierley, A. S., and Cottier, F. 2016. Moonlight drives ocean-scale mass vertical migration of zooplankton during the Arctic winter. Curr. Biol. 26:244-51. doi: 10.1016/j.cub.2015.11.038

5. Kaartvedt, S. 2008. Photoperiod may constrain the effect of global warming in arctic marine systems. J. Plankton Res. 30:1203-6. doi: 10.1093/plankt/fbn075

6. Manno, C., Stowasser, G., Enderlein, P., Fielding, S., and Tarling, G. A. 2015. The contribution of zooplankton faecal pellets to deep-carbon transport in the Scotia Sea (Southern Ocean). Biogeosciences 12:1955-65. doi: 10.5194/bg-1 2-1955-2015

7. Kremer, P., and Kremer, J. N. 1988. Energetic and behavioral-implications of pulsed food availability for zooplankton. Bull. Mar. Sci. 43:797-809.

SUBMITTED: 29 October 2019; ACCEPTED: 20 March 2020;

PUBLISHED ONLINE: 30 April 2020.

EDITED BY: Kirsty C. Crocket, University of Edinburgh, United Kingdom 

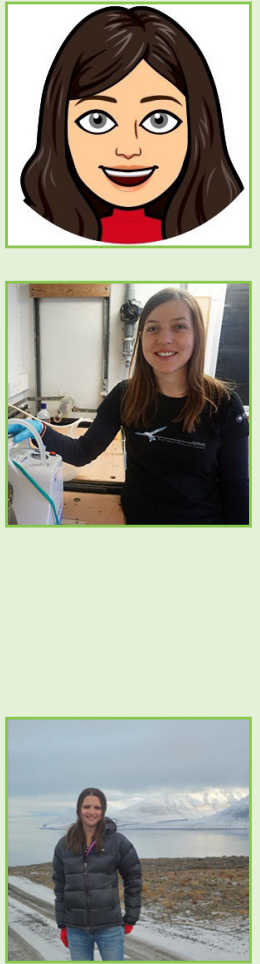

CITATION: Freer JJ and Hobbs L (2020) DVM: The World's Biggest Game of Hide-and-Seek. Front. Young Minds 8:44. doi: 10.3389/frym.2020.00044

CONFLICT OF INTEREST: The authors declare that the research was conducted in the absence of any commercial or financial relationships that could be construed as a potential conflict of interest.

COPYRIGHT (c) 2020 Freer and Hobbs. This is an open-access article distributed under the terms of the Creative Commons Attribution License (CC BY). The use, distribution or reproduction in other forums is permitted, provided the original author(s) and the copyright owner(s) are credited and that the original publication in this journal is cited, in accordance with accepted academic practice. No use, distribution or reproduction is permitted which does not comply with these terms.

\section{YOUNG REVIEWER}

\section{GEMMA, AGE: 16}

My name is Gemma, I am 16 years old and I love playing sports and music.

\section{AUTHORS}

\section{JENNIFER J. FREER}

I am a marine scientist at the British Antarctic Survey and have always been fascinated by life in the oceans. My work aims to help understand how marine animals are distributed, what controls their distributions, and how climate change might affect them. I study zooplankton and pelagic fishes found in the polar oceans and use model-based tools to predict their future ranges. Whether it is spending time on a ship, beach walks, or surfing, I am happiest on or by the sea. *jenfree@abas.ac.uk

\section{LAURA HOBBS}

I have always considered myself a thalassophile-a lover of the oceans. For the past 10 years or so, I have spent as much time as possible working in the Arctic. I find it an absolutely fascinating place to study. The light cycle is completely unique, and the midnight sun and the polar night present really interesting questions in ecology, particularly with respect to animals that respond to light (such as zooplankton). I use lots of different methods to study zooplankton, and some of this involves installing instruments in the Arctic Ocean for a year at a time. 